\title{
The impact of rapid economic growth and globalization on zinc nutrition in South Korea
}

\author{
In-Sook Kwun ${ }^{1, *}$, Mi-Sook Do ${ }^{1}$, Hae-Rang Chung ${ }^{2}$ †, Yang ha Kim ${ }^{3}$ and John H Beattie ${ }^{4}$ \\ ${ }^{1}$ Department of Food Science and Nutrition, Andong National University, 388 Songchundong, Andong, \\ Kyungpook 760-749, South Korea: ${ }^{2}$ Korea Health Industry Development Institute, Seoul, South Korea: \\ ${ }^{3}$ Department of Nutritional Science and Food Management, Ewha Womans University, Seoul, South Korea: \\ ${ }^{4}$ Division of Vascular Health, Rowett Institute of Nutrition and Health, University of Aberdeen, Aberdeen, UK
}

Submitted 26 November 2007: Accepted 18 August 2008: First published online 27 October 2008

\begin{abstract}
Objective: Zn deficiency may be widespread in Asian countries such as South Korea. However, dietary habits have changed in response to rapid economic growth and globalization. Zn nutrition in South Koreans has therefore been assessed during a period (1969-1998) of unprecedented economic growth.

Design and methods: Cross-sectional food consumption data from the Korean National Nutrition Survey Reports (KNNSR) of South Korea at four separate time points (1969, 1978, 1988 and 1998) were used to calculate Zn, Ca and phytate intakes using various food composition tables, databases and literature values. Nutrient values in local foods were cited from their analysed values.

Results: Average Zn intake was 5.8, 4.8 and 5.3 mg/d for 1969, 1978 and 1988 respectively, increasing to $7 \cdot 3 \mathrm{mg} / \mathrm{d}$ in 1998 (73\% of the Korean Dietary Reference Intake). The phytate:Zn molar ratio decreased from 21 to 8 during the study period. Dietary $\mathrm{Zn}$ depletion due to marked decreases in cereal consumption, particularly barley which has a low Zn bioavailability, was counterbalanced by marked increases in the consumption of meat and fish, which are also Zn-rich foods. Reduced phytate consumption coincident with increased $\mathrm{Zn}$ intake suggests that Zn bioavailability also improved, particularly by 1998 .

Conclusions: Although total $\mathrm{Zn}$ intake was not greatly affected over the initial period of economic growth in South Korea (1969-1988), Zn contributions from different food sources changed markedly and both $\mathrm{Zn}$ intake and potential bioavailability were improved by 1998. The study may have implications for $\mathrm{Zn}$ nutrition in other Asian countries currently experiencing rapid economic growth.
\end{abstract}

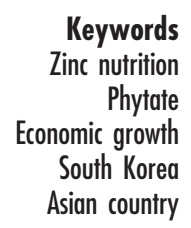

The dietary habits and nutritional adequacy of populations in developing countries may change in response to improved economic prosperity and global influences. In general, poor infrastructure and data management systems in developing countries, combined with a lack of nutrient data for local food products ${ }^{(1,2)}$, can impede a comprehensive temporal analysis of changing nutritional intake. South Korea has emerged from a very poor economic status in the 1950s to become the eleventh world economic power at the present time. Although some developed Western countries periodically report dietary $\mathrm{Zn}$ intake data from nationwide nutritional surveys ${ }^{(3)}$, there are few reliable reports of $\mathrm{Zn}$ intake in Asian developing countries. There are some previous limited Asian studies, such as in South Korea ${ }^{(4,5)}$ and China ${ }^{(6)}$. In addition to low $\mathrm{Zn}$ intakes, dietary factors such as phytic

$\dagger$ Present address: Nutrition for the Future Inc., Seoul, South Korea. acid influence $\mathrm{Zn}$ absorption ${ }^{(7)}$. However, the nutrient composition of local staple foods, including $\mathrm{Zn}$, phytate and other factors affecting $\mathrm{Zn}$ absorption, has not been systematically determined. The Korean National Nutrition Survey (KNNS) has produced reliable and comprehensive data on food intakes in different population groups since 1969. Since $\mathrm{Zn}$ deficiency is thought to be prevalent in South Korea, the present paper focuses on changing $\mathrm{Zn}$ intake during years of rapid economic growth.

Phytate (myo-inositol hexaphosphate) is well known to decrease $Z n$ bioavailability ${ }^{(7-9)}$ and a mathematical model of $\mathrm{Zn}$ absorption as a function of dietary $\mathrm{Zn}$ and phytate has been published ${ }^{(10)}$. Phytate is present at high levels in unrefined cereals, legumes, nuts and seeds, and most of the $\mathrm{P}$ in these foods is present mostly as phytate ${ }^{(11)}$. Phytate contains negatively charged phosphate ligands which complex with positively charged cations such as $\mathrm{Zn}^{2+}, \mathrm{Ca}^{2+}, \mathrm{Mg}^{2+}$ and $\mathrm{Fe}^{2+}$. Absorption of these metals 
from the small intestine is therefore inhibited due to their chelation by phytate ${ }^{(12)}$. $\mathrm{Zn}$ absorption is reported to be typically $15 \%$ or less from high-phytate diets ${ }^{(13,14)}$. Asian populations, such as in Korea, Japan and China, consume soyabean products and various grains containing large amounts of phytate. The phytate: $\mathrm{Zn}$ molar ratio may be helpful for the nutritional assessment of dietary $\mathrm{Zn}$ $\operatorname{adequacy}^{(7,13-16)}$. Another potential inhibitory factor for $\mathrm{Zn}$ bioavailability is $\mathrm{Ca}$, which potentiates the inhibitory effect of phytate by the formation of insoluble phytate$\mathrm{Ca}-\mathrm{Zn}$ complexes. Thus, phytate $\times \mathrm{Ca}: \mathrm{Zn}$ has also been used for assessment of $\mathrm{Zn}$ status ${ }^{(15)}$. Therefore, the effect of changes in dietary habits on the nutritional value of consumed $\mathrm{Zn}$ may be better predicted by taking into account both the $\mathrm{Ca}$ and phytate intakes.

Our objective was to examine the changing patterns of $\mathrm{Zn}$ intake, in relation to $\mathrm{Ca}$ and phytate intake, over a 30-year period of high economic growth in South Korea from 1969. In the present study, we evaluated how improved economic prosperity and globalization in South Korea have affected both the quantity and quality of dietary $\mathrm{Zn}$ consumed, in addition to influencing the dietary intake of $\mathrm{Ca}$ and phytate, which may inhibit $\mathrm{Zn}$ absorption. We speculated that improved prosperity would improve $\mathrm{Zn}$ nutrition because some $\mathrm{Zn}$-rich foods, such as animal meat, are expensive to produce and are only consumed in quantity in more affluent urbanized societies $^{(17)}$. Indeed, the average annual increase in meat consumption in South Korea (10\%) during the period of rapid economic growth (1964-1999) was one of the highest recorded in the developing world ${ }^{(18)}$. To our knowledge, the present study is the first comprehensive report on temporal changes of $\mathrm{Zn}$ intake in an Asian population experiencing such a marked change in economic circumstances.

\section{Materials and methods}

\section{Korean National Nutrition Survey Reports (1969-1998)}

To determine $\mathrm{Zn}$ nutritional assessment during the past three decades (1969-1998) in South Koreans, food consumption data were obtained from the Korean National Nutrition Survey Reports (KNNSR) at 10-year intervals (1969, 1978, 1988 and 1998) ${ }^{(19)}$. We selected 10-year intervals between 1969 and 1998 in order to identify major changes in the quality and quantity of dietary $\mathrm{Zn}$, $\mathrm{Ca}$ and phytate intakes over a period of unprecedented rapid economic growth.

The first KNNS was conducted for the civilian, noninstitutionalized population of Koreans in each household in 1969, the second in 1973, then annually up to 1995, and every 3 years thereafter. Until 1998, food consumption for the estimation of dietary intake was measured by a trained interviewer weighing every food the surveyed household members ate at home for two consecutive days and then dividing by the number of members in the household to estimate individual food consumption. However, since 1998, individual food consumption has been obtained from food records and dietary examinations, conducted by interview by trained dietitians, on two consecutive weekdays. Each person's daily food intake in the sample household was adjusted as a percentage of the daily food intake of a normal male adult, whose daily food intake was given as $1 \cdot 0$. The normal male adult was defined as a person $172.0 \mathrm{~cm}$ tall, weighing $66 \mathrm{~kg}$, aged 20-29 years, and working at a medium level of labour ${ }^{(20,21)}$.

The surveys were conducted nationwide in the autumn around September by the Korean Ministry of Health and Welfare and the Korean Nutrition Society. In 1969 and since 1973, representative sample households of the nation were selected by using a multistage stratified sampling, a multistage cluster sampling or a sampling method with probability proportional to size, depending on the year ${ }^{(20)}$. The number of households surveyed ranged from about 500 to 2000 until 1988, and then 2000 households nationwide after that time. In the 1998 survey, each survey unit was composed of twenty households, and there were a total of 100 survey units which were representative for South Korea as a whole. This yielded representative data from 2000 households from city and semi-rural areas in different parts of the whole country.

\section{Food intake data in the Korean National Nutrition Survey Reports}

Of the more than a few hundred to a few thousand food items that were consumed by normal Koreans and originally reported in the KNNS over the 30-year period, the KNNSR reported and categorized only selected food items that were quantitatively important and frequently consumed. We used these KNNSR food items for nutrient intake determination. The KNNSR presented food intake values as the average daily per capita intake of each food item adjusted to that of a normal adult male. Up to thirteen plant and five animal food groups were categorized, and the selected food items included on the KNNSR increased from sixty-eight items in 1969 to 474 items in 1998 (Table 1).

\section{Assessment of $\mathrm{Zn}$, Ca and phytate intakes and comparison with dietary reference intakes for Koreans}

The assessment of dietary intakes of $\mathrm{Zn}$, Ca and phytate has been described in a previous study ${ }^{(4)}$. Briefly, daily $\mathrm{Zn}$ and $\mathrm{Ca}$ intakes were calculated from various food composition tables, databases and literature values. $\mathrm{Zn}$ values for Korean local food items were obtained from a selected reference ${ }^{(22)}$. For food $\mathrm{Zn}$ and $\mathrm{Ca}$ values which were not cited in literature, substituted values for similar foods in the same food group were used. The weight in 
grams of each food item on the KNNSR was multiplied by the published values for $\mathrm{Zn}$ or Ca content and all values were summed to give the average daily $\mathrm{Zn}$ or Ca content per capita. In contrast to a previous study ${ }^{(4)}$, the analysed phytate values for local foods were used ${ }^{(23)}$. Adjustments were made, when necessary, to take into account any known changes in phytate content arising from food processing and preparation methods.

Dietary $\mathrm{Zn}$ and Ca intakes were compared with two of the Korean Dietary Reference Intake (KDRI) values, i.e. the Estimated Average Requirement (EAR) and the Recommended Intake (RI) for an adult male (20-29 years old), since the per capita KNNSR data are calculated for this age range and gender ${ }^{(21)}$. The EAR, which replaces the previous Recommended Daily Allowance, is the daily intake value that is estimated to meet the requirement, as defined by a specified indicator of adequacy, in $50 \%$ of the individuals in group. At this level of intake, the other $50 \%$ of individuals in a specified group would not have their nutritional needs met. The RI is the average daily dietary intake level that is sufficient to meet the nutrient 'requirement' of nearly all (97-98\%) healthy individuals in a specific group. The RI is intended primarily for use as a target intake by individuals. A requirement is defined as the lowest continuing intake level of a nutrient that, for a

Table 1 Numbers of food items and food groups described in the Korean National Nutrition Survey Reports for major food consumption by South Koreans during the period 1969-1998

\begin{tabular}{llrc}
\hline Sample year & Food type & Food groups & Food items \\
\hline 1969 & Plant & 10 & 46 \\
& Animal & 5 & 22 \\
1978 & Total & 15 & 68 \\
& Plant & 10 & 46 \\
& Animal & 5 & 22 \\
1988 & Total & 15 & 68 \\
& Plant & 13 & 79 \\
\multirow{4}{*}{1998} & Animal & 5 & 39 \\
& Total & 18 & 118 \\
& Plant & 13 & 337 \\
& Animal & 5 & 137 \\
& Total & 18 & 474 \\
\hline
\end{tabular}

specified indicator of adequacy, will maintain a defined level of nutriture in an individual. The molar ratio of phytate: $\mathrm{Zn}$ and the millimolar ratio of phytate $\times \mathrm{Ca}: \mathrm{Zn}$ were calculated using a phytate molecular weight of $660 \cdot 1$.

\section{Results}

\section{Zn, Ca and phytate intakes in comparison with the South Korean Estimated Average Requirement and Recommended Intake values}

Average daily intakes of $\mathrm{Zn}, \mathrm{Ca}$ and phytate per capita and their percentage of the EAR and RI values are shown in Table 2. During the first two decades (1969-1988), per capita $\mathrm{Zn}$ intake in South Koreans was low (5·8, 4.8 and $5.3 \mathrm{mg} / \mathrm{d}$ for 1969, 1978 and 1988, respectively), but increased markedly from 1988 to 1998 (7.3 mg/d). Compared with the RI for $\mathrm{Zn}(10 \mathrm{mg} / \mathrm{d}), \mathrm{Zn}$ intake increased from $58 \%$ of the RI in 1969 to $73 \%$ in 1998. Zn intake in 1998 was $90 \%$ of the EAR for $\mathrm{Zn}(8 \cdot 1 \mathrm{mg} / \mathrm{d})$.

The daily average Ca intake of South Koreans increased two-fold between 1969 and 1998. However, the daily intakes of Ca over the 30-year study period were around 30-70\% lower than the EAR for Ca (Table 2). In 1998, per capita Ca intake $(465.9 \mathrm{mg} / \mathrm{d})$ was $67 \%$ of the RI $(700 \mathrm{mg} / \mathrm{d})$ and $80 \%$ of the EAR $(580 \mathrm{mg} / \mathrm{d})$. Per capita phytate intake of South Koreans was about $1 \mathrm{~g} / \mathrm{d}$ during the period 1969-1978, after which it decreased consistently and had almost halved by 1998 (Table 2).

\section{Ratios of phytate:Zn and phytate $\times$ Ca:Zn}

The molar ratio for phytate: $\mathrm{Zn}$ and millimolar ratio of phytate $\times$ Ca:Zn for the South Korean diet are shown in Table 2 . Molar ratios of phytate:Zn in 1969, 1978 and 1988 were greater than 15, which may decrease $\mathrm{Zn}$ absorption, but decreased to $8 \cdot 2$ by 1998 due to both increased Zn intake and decreased phytate intake. The millimolar ratios of phytate $\times$ Ca:Zn during the 30-year period were 96-136 but, unlike the phytate: $\mathrm{Zn}$ ratio, did not decrease markedly in 1998 because of the substantial increase in Ca intake.

Table 2 Representative dietary intakes of zinc, calcium and phytate in South Koreans over 30 years (1969-1998)* and comparison with the Korean DRIt for zinc and calcium

\begin{tabular}{|c|c|c|c|c|c|c|c|c|c|c|}
\hline \multirow[b]{3}{*}{ Year } & \multirow{3}{*}{$\begin{array}{c}\text { GDIf } \\
\text { (\% of USA) }\end{array}$} & \multicolumn{9}{|c|}{ Per capita dietary intake } \\
\hline & & \multicolumn{3}{|c|}{$\mathrm{Zn}$} & \multicolumn{3}{|c|}{$\mathrm{Ca}$} & \multirow{2}{*}{$\begin{array}{l}\text { Phytate } \\
\text { (mg/d) }\end{array}$} & \multirow{2}{*}{$\begin{array}{l}\text { Phytate:Zn } \\
\text { (molar ratio) }\end{array}$} & \multirow{2}{*}{$\begin{array}{l}\text { Phytate } \times \mathrm{Ca}: \mathrm{Zr} \\
\text { (millimolar ratio) }\end{array}$} \\
\hline & & $\mathrm{mg} / \mathrm{d}$ & $\%$ of EAR & $\%$ of $\mathrm{RI}$ & $\mathrm{mg} / \mathrm{d}$ & $\%$ of EAR & $\%$ of $\mathrm{RI}$ & & & \\
\hline 1969 & $14 \cdot 3$ & $5 \cdot 8$ & 72 & 58 & $224 \cdot 4$ & 39 & 32 & 1032 & $17 \cdot 7$ & 98.9 \\
\hline 1978 & $22 \cdot 3$ & $4 \cdot 8$ & 59 & 48 & $233 \cdot 9$ & 40 & 33 & 1015 & $21 \cdot 0$ & $122 \cdot 5$ \\
\hline 1988 & $35 \cdot 5$ & $5 \cdot 3$ & 65 & 53 & $340 \cdot 0$ & 59 & 49 & 857 & $16 \cdot 0$ & $136 \cdot 1$ \\
\hline 1998 & $42 \cdot 4$ & $7 \cdot 3$ & 90 & 73 & $465 \cdot 9$ & 80 & 67 & 605 & $8 \cdot 2$ & $95 \cdot 6$ \\
\hline
\end{tabular}

*Food consumption data for the calculation of $\mathrm{Zn}$ and $\mathrm{Ca}$ intakes were taken from the National Health and Nutrition Surveys for South Koreans of four consecutive years $(1969,1978,1988$ and 1998) every 10 years, as described in Materials and methods.

tTwo values in the Korean Dietary Reference Intakes (DRI), the Estimated Average Requirement (EAR) and the Recommended Intake (RI), were used for the comparison of nutrient intakes. Zn EAR and RI for Korean DRI are 8.1 and $10 \mathrm{mg} / \mathrm{d}$ respectively and Ca EAR and RI are 580 and $700 \mathrm{mg} / \mathrm{d}$ respectively for an adult male (20-29 years old) who was considered as 'per capita' on the KNNSR (Korean National Nutrition Survey Reports).

¥South Korean gross domestic income (GDI) per capita as a dollar percentage of that in the USA ${ }^{(24)}$. 
Major food groups and food items for $\mathrm{Zn}, \mathrm{Ca}$ and phytate intakes

The amount and percentage contribution of each food group to the daily intakes of $\mathrm{Zn}$, Ca and phytate are shown in Table 3. The thirteen plant and five animal food groups categorized in the KNNSR are represented. Table 4 lists the major food sources of $\mathrm{Zn}$, Ca and phytate in the Korean diet over the 30-year study period and their changing contribution to the total intake for each year. Data from Tables 2-4 are summarized in Fig. 1, to demonstrate the underlying explanation for changes in total $\mathrm{Zn}$ intake between 1969 and 1998 and the association between sources of dietary $\mathrm{Zn}$ and gross domestic income (GDI) ${ }^{(24)}$.

Over the 30-year period of 1969-1998, most of the dietary $\mathrm{Zn}$ in the Korean diet came from 'cereal and grain products', 'legumes and their products' and 'vegetables', which accounted for almost 84\% in 1969 and 42\% in 1998 (Table 3). Animal food sources like 'beef, pork and their products' and 'fish and shellfish' accounted for $4 \%$ of dietary $\mathrm{Zn}$ in 1969 and increased to 35\% in 1998 (Table 3). From 1969 to 1988, Zn intake from plant food groups decreased, while Zn intake from animal groups increased (Fig. 1, upper panel). However, an increased vegetable intake between 1988 and 1998, which was probably a consequence of increased health awareness during this period, reversed the trend for plant food Zn intake. In 1969, Zn from beef and pork was of minor significance but by 1988-1998, they were together the most important source of dietary $\mathrm{Zn}$ (Table 4). Conversely, barley $\mathrm{Zn}$ showed a precipitous decline between 1969 and 1988 (Table 4 and Fig. 1, bottom panel). Rice, as the most important staple in the Korean diet, was a major source of dietary $\mathrm{Zn}$ intake over 30 years, although its contribution decreased notably in 1998 (Table 4).

Total Ca intake showed a different pattern to total $\mathrm{Zn}$ intake, and increased steadily from 1969 to 1998. However, the underlying trends for Ca-rich foods were similar to those for $\mathrm{Zn}$-rich foods, with contributions from 'cereal and grain products' decreasing from 31\% to $7 \%$ over three decades and $\mathrm{Ca}$ intake from 'milk and dairy products' increasing from $2 \%$ to $20 \%$ (Table 3). From 1989 to 1998, the principal Ca source, which had previously been grain products, was milk (Table 4). Of the foods consumed by South Koreans over three decades, 'cereals and grain products' supplied most of the dietary phytate (74-84\%), followed by 'legumes and their products', 'vegetables' and 'seasonings' (Table 3). The high phytatecontaining foods in the Korean diet were rice, barley and soyabean products, such as soyabean paste, soyabeans, soya sauce and tofu (Table 4).

\section{Discussion}

The current study presents a rare profile of long-term changes in the dietary intakes of $\mathrm{Zn}$, Ca and phytate due to marked and rapid improvement in economic status and globalization of a human population. It also reveals the changes in food preference that accompany economic prosperity and that impact quantitatively on the consumption and availability of dietary $\mathrm{Zn}$. Values for total $\mathrm{Zn}$ intake (Table 2) were lower than those reported previously ${ }^{(4)}$ and indicate that many Koreans were potentially Zn-deficient, especially pre-1998. Casual examination of the trend in total Zn intake from 1969 to 1998 might suggest a delayed response of consumers to increasing economic prosperity, which was evident even by 1978 . However, the monitoring of $\mathrm{Zn}$ intake from food groups clearly shows a profound underlying change in dietary habits (Fig. 1).

While Zn intake from plant foods decreased up to 1988 , there was a consistent increase in $\mathrm{Zn}$ intake from animal foods throughout the study period. Paradoxically, the $17 \%$ reduction in total $\mathrm{Zn}$ intake between 1969 and 1978 can be directly linked to improved food choice and availability. During years of nutritional insufficiency in the 1950 and 1960s, Koreans used barley to mix with rice because of insufficient rice production. As regards socioeconomic status and taste, barley was considered a poor substitute for rice and the rapid decline in barley $\mathrm{Zn}$ between 1969 and 1978, which accounts for the reduction in total $\mathrm{Zn}$ (Fig. 1), can therefore be explained by improvements in rice production, increasing dietary choice and improved prosperity. By 1988, the increasing affordability and desirability of beef, pork, poultry, fish, shellfish and other animal products, which are Zn-rich foods, had reversed this decline in total $\mathrm{Zn}$ intake. In addition, vegetable and fruit intake increased substantially between 1988 and 1998, further boosting the intake of $\mathrm{Zn}$. Thus the trend in total $\mathrm{Zn}$ intake between 1969 and 1988 can be quantitatively accounted for by changing food selection of three food groups (meat and poultry, fruit and vegetables, fish and shellfish) and one cereal (barley), as demonstrated in Fig. 1. The $\mathrm{Zn}$ intake by 1998 was further increased by a variety of additional foods, including those from outside Korea. Although milk has traditionally been used in Korea, its use has changed and increased particularly due to Western cultural influences. By 1998, milk was therefore a significant source of dietary $\mathrm{Zn}$ and a principal source of Ca (Table 4).

Even within a food group, there were marked changes in food item preference in $\mathrm{Zn}$ intake. Wheat flour was traditionally used for noodle production and, for the purposes of the present study, Zn from this source (which declined during the study period) has been separated from that of wheat products (bread, crackers, sponge cake), which are foods arising entirely from globalization influences and increasing markedly during the period 1988-1998. Shellfish are a rich source of $\mathrm{Zn}$ and fresh and pickled clams were one of the traditional components of the Korean diet until 1978. Oysters have become a more popular food but were not easily affordable prior to the implementation of culture techniques resulting in improved availability and affordability of this shellfish. 


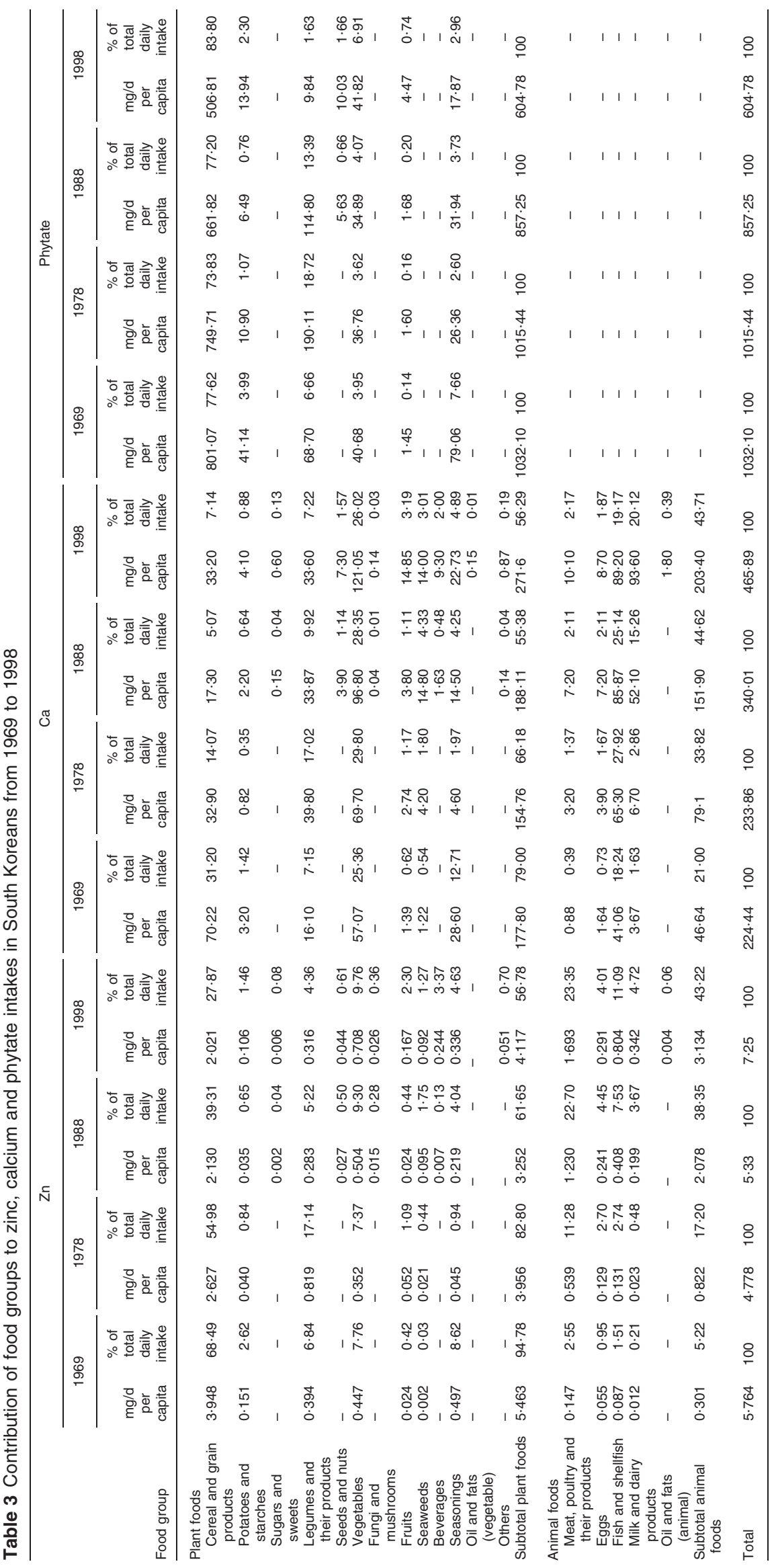


Table 4 Change in dietary intakes of zinc, calcium and phytate from selected zinc-, calcium- and phytate-rich foods over the period 1969-1998. The year of highest intake in general for each food is shown in bold and the foods are ranked according this criterion, which indicates their availability, affordability and preferred selection over time*

\begin{tabular}{|c|c|c|c|c|c|c|c|c|c|c|c|c|c|c|}
\hline \multirow[b]{2}{*}{ Zn foods } & \multicolumn{4}{|c|}{ Year } & \multirow[b]{2}{*}{ Ca foods } & \multicolumn{4}{|c|}{ Year } & \multirow[b]{2}{*}{ Phytate foods } & \multicolumn{4}{|c|}{ Year } \\
\hline & 1969 & 1978 & 1988 & 1998 & & 1969 & 1978 & 1988 & 1998 & & 1969 & 1978 & 1988 & 1998 \\
\hline Red pepper paste & 0.30 & $<0.01$ & 0.06 & 0.09 & Loach (fish) & $8 \cdot 1$ & $4 \cdot 4$ & ND & $3 \cdot 7$ & Sesame toasted & $21 \cdot 0$ & ND & $4 \cdot 85$ & $9 \cdot 7$ \\
\hline Green pepper & $0 \cdot 17$ & 0.04 & ND & ND & Soya sauce & $7 \cdot 0$ & $4 \cdot 4$ & $2 \cdot 1$ & $1 \cdot 9$ & Small red bean & $11 \cdot 0$ & $4 \cdot 5$ & $4 \cdot 3$ & 0.5 \\
\hline Potato & $0 \cdot 15$ & 0.04 & 0.02 & 0.06 & Sesame seeds & $15 \cdot 9$ & ND & ND & $6 \cdot 9$ & Barley & $216 \cdot 9$ & $103 \cdot 8$ & $9 \cdot 5$ & $9 \cdot 7$ \\
\hline Barley & $2 \cdot 10$ & 0.60 & 0.05 & 0.05 & Barley & $51 \cdot 6$ & $14 \cdot 2$ & $1 \cdot 3$ & $1 \cdot 3$ & Wheat flour & $52 \cdot 8$ & $44 \cdot 2$ & $18 \cdot 7$ & $6 \cdot 6$ \\
\hline Pumpkin & 0.15 & $0 \cdot 10$ & 0.02 & 0.04 & Pumpkin & $23 \cdot 1$ & $14 \cdot 9$ & 3.6 & $5 \cdot 5$ & Soya sauce & 55.9 & $26 \cdot 2$ & $16 \cdot 5$ & $14 \cdot 9$ \\
\hline Wheat flour & $0 \cdot 18$ & 0.15 & 0.06 & 0.02 & Wheat flour & $7 \cdot 0$ & $5 \cdot 9$ & $2 \cdot 5$ & 0.9 & Potato & $41 \cdot 0$ & $10 \cdot 9$ & $5 \cdot 6$ & $12 \cdot 1$ \\
\hline Soyabean & $0 \cdot 11$ & 0.50 & $0 \cdot 12$ & $0 \cdot 14$ & Radish leaf kimchi & $13 \cdot 4$ & $28 \cdot 4$ & $2 \cdot 3$ & $9 \cdot 4$ & Garlic & $20 \cdot 2$ & $12 \cdot 8$ & $16 \cdot 0$ & $14 \cdot 1$ \\
\hline Radish leaf kimchi & 0.03 & 0.07 & 0.01 & 0.02 & Soyabean paste & $8 \cdot 7$ & $12 \cdot 3$ & $5 \cdot 3$ & $4 \cdot 6$ & Soyabean paste & $24 \cdot 9$ & $34 \cdot 9$ & $15 \cdot 0$ & $13 \cdot 2$ \\
\hline Soyabean paste & 0.20 & $0 \cdot 30$ & $0 \cdot 13$ & 0.11 & Soyabean & $5 \cdot 9$ & $27 \cdot 0$ & $6 \cdot 4$ & $7 \cdot 4$ & Soyabean & $32 \cdot 9$ & $150 \cdot 7$ & 36 & $41 \cdot 1$ \\
\hline Rice & $1 \cdot 70$ & 1.90 & $2 \cdot 00$ & $1 \cdot 45$ & Cabbage & $1 \cdot 2$ & 8.9 & $7 \cdot 0$ & $5 \cdot 8$ & Radish leaf kimchi & $5 \cdot 7$ & $12 \cdot 2$ & ND & ND \\
\hline Mackerel & $<0.01$ & ND & 0.13 & 0.01 & Anchovy & $29 \cdot 7$ & $58 \cdot 1$ & $67 \cdot 1$ & $38 \cdot 7$ & Pumpkin & $7 \cdot 0$ & $4 \cdot 5$ & $1 \cdot 1$ & $1 \cdot 7$ \\
\hline Tofu & ND & ND & $0 \cdot 13$ & $0 \cdot 12$ & Rice & $11 \cdot 1$ & $12 \cdot 7$ & $13 \cdot 3$ & $9 \cdot 7$ & Rice & $529 \cdot 3$ & $600 \cdot 8$ & $632 \cdot 7$ & $459 \cdot 4$ \\
\hline Cabbage kimchi & 0.06 & 0.03 & $0 \cdot 18$ & $0 \cdot 15$ & Cabbage kimchi & $5 \cdot 0$ & $7 \cdot 9$ & $44 \cdot 9$ & $37 \cdot 8$ & Soyabean curd & ND & ND & $74 \cdot 4$ & $70 \cdot 2$ \\
\hline Egg & 0.05 & $0 \cdot 13$ & $0 \cdot 24$ & 0.28 & Tofu & ND & ND & $26 \cdot 7$ & $25 \cdot 2$ & Cabbage kimchi & $1 \cdot 0$ & $1 \cdot 5$ & $8 \cdot 8$ & $6 \cdot 2$ \\
\hline Beef & $0 \cdot 10$ & 0.40 & $0 \cdot 80$ & $1 \cdot 06$ & Radish root & $0 \cdot 8$ & 0.8 & $14 \cdot 5$ & $13 \cdot 2$ & Glutinous rice & ND & ND & ND & $6 \cdot 5$ \\
\hline Pork & 0.04 & 0.07 & $0 \cdot 30$ & 0.47 & Laver & $<0.1$ & 0.5 & $10 \cdot 1$ & $6 \cdot 4$ & Foxtail millet & ND & ND & ND & $6 \cdot 0$ \\
\hline Milk & ND & 0.02 & 0.19 & 0.29 & Wheat products & ND & ND & ND & $13 \cdot 5$ & & & & & \\
\hline Shellfish & 0.02 & 0.02 & 0.05 & $0 \cdot 14$ & Egg & $1 \cdot 6$ & 3.9 & $7 \cdot 2$ & 8.5 & & & & & \\
\hline Wheat products & ND & ND & ND & $0 \cdot 14$ & Milk & $3 \cdot 7$ & $6 \cdot 7$ & $51 \cdot 3$ & $80 \cdot 0$ & & & & & \\
\hline Green tea & ND & ND & ND & 0.15 & Green onion & $2 \cdot 0$ & $5 \cdot 4$ & $9 \cdot 4$ & $9 \cdot 6$ & & & & & \\
\hline Salted small fish & ND & ND & ND & $0 \cdot 12$ & Salted small fish & ND & ND & ND & $9 \cdot 6$ & & & & & \\
\hline
\end{tabular}

ND, not determined.

*Values were calculated from the daily food intakes in the 1969 to 1998 KNNSR (Korean National Nutrition Survey Reports).

In contrast, consumption of clams has declined (data not shown).

The interpretation of changes in $\mathrm{Ca}$ and phytate, which were inversely related over time, is less complex than that for Zn. Food selection since 1969 has increasingly favoured Ca-rich foods, such as milk and meat, which do not contain phytate. Consumption of cereals and legumes, which are major contributors of $\mathrm{Ca}$ and phytate in the Korean diet, has also generally declined over time. However, as early as 1998, the influence of increasing public interest and awareness in health foods on food selection could be detected. Like barley, foxtail millet and other phytate-rich cereals (e.g. sorghum, buckwheat) were added to rice in 1969 , when rice availability was insufficient, and their use declined during early years of economic recovery. However, by 1998, they were increasingly being selected as a rice supplement for their perceived health benefits, and so phytate from these sources increased.

Given that dietary $\mathrm{Zn}$ intake did not change markedly up to 1988 and increased in 1998, and that phytate intake decreased consistently over time, it follows that the phytate:Zn molar ratio had substantially decreased by 1998. The phytate:Zn molar ratios calculated for 1969-1988 are consistent with the high values recorded previously in developing countries ${ }^{(2,14)}$ and specifically in Asia $^{(4,6,25)}$, and have been shown to have a significant negative influence on intestinal $\mathrm{Zn}$ absorption ${ }^{(2,9,15)}$. As regards increased relative risk of $\mathrm{Zn}$ deficiency, a low absorption efficiency for $\mathrm{Zn}$ has been associated with a phytate:Zn molar ratio of $>15^{(26)}$. By 1998 , the dietary phytate:Zn molar ratio $(8 \cdot 2)$ was more comparable with the diets of Westernized countries than with traditional diets of Asian countries ${ }^{(27)}$. Critically, however, it is the urban populations that are driving this decline in phytate: $\mathrm{Zn}$ ratios and the rural populations, which tend to be much less affluent, have been less influenced by changes in national economic status and retain a more restricted traditional Korean diet ${ }^{(4)}$. Gibson and co-workers proposed that a millimolar ratio of phytate $\times \mathrm{Ca}: \mathrm{Zn}$ may more accurately predict the influence of this interaction on $\mathrm{Zn}$ availability, and a $\mathrm{Zn}$ deficiency risk threshold ratio of 200 was suggested ${ }^{(15)}$. In the present study, this threshold was not exceeded. Nevertheless, a ratio of $>98$, which was calculated for all sample times in the present study, is higher than may be expected in Western diets ${ }^{(27)}$.

It is very clear that food choice expanded greatly over the 30 years of this study period, which was mostly a consequence of globalization. As an illustration of globalization influences in South Korea, we used statistics from the FAO database (FAOSTAT) ${ }^{(28)}$ to identify nine foods (sugar, olive oil, lemons, bananas, pineapples, coffee, cocoa beans (chocolate), wine and cream) that could be described as globalization indicators, because in 1969 they were not produced in Korea and were not widely consumed by Koreans. Consumption of these foods imported from outside Korea increased steadily during the study period, showing an average of a three- to four-fold increase during each of the three 9- to 10-year periods from 1969 until 1998. Some foods such as sugar were already imported and in limited domestic use for food products in 1969, but others such as cream arrived in Korea later in the study period. The use of foods from outside Korea has not greatly influenced dietary $\mathrm{Zn}$ intake by Koreans, but non-Korean cultural influences have affected eating habits, which may in turn affect Zn consumption. 


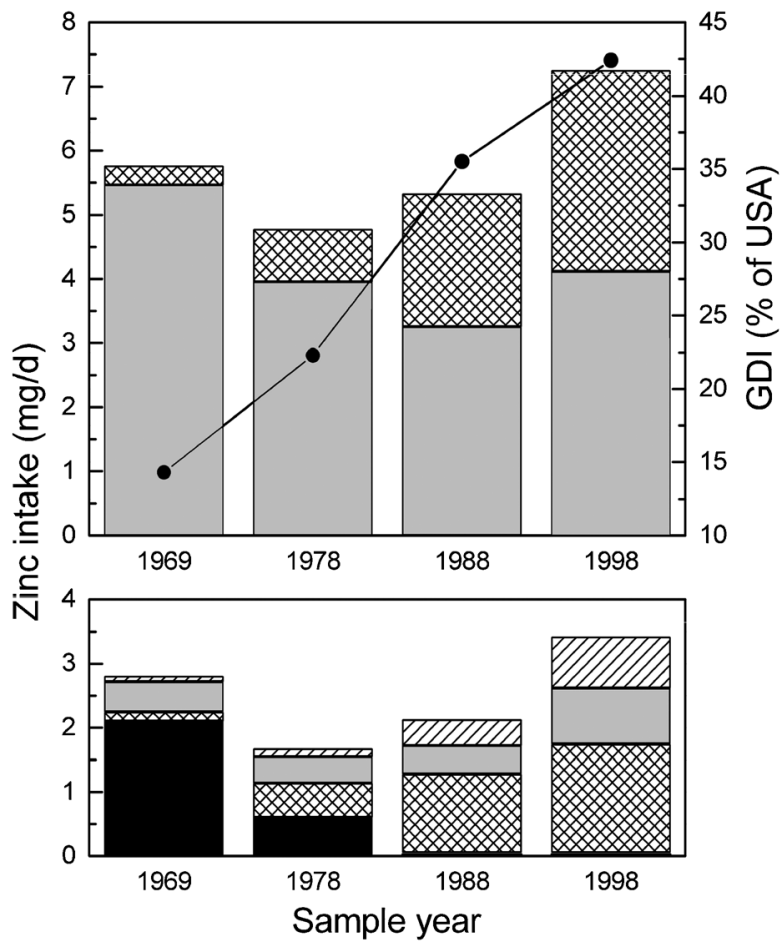

Fig. 1 Average total dietary intake of zinc by South Koreans (mg/d per capita) and contributions of zinc from animal (因) and plant foods ( $\square$; upper panel), with a more detailed presentation of 'indicator' foods ( $\boldsymbol{\square}$, barley; $\otimes$, meat and poultry; $\square$, vegetables and fruit; $\square$, fish and shellfish; lower panel) which together mostly account for the changes in total zinc intake. Also shown on the upper panel is the change in South Korean gross domestic income (GDI) per capita (- - ), as a percentage of that for the USA, over the 30 years of the study period

Although the principal $\mathrm{Zn}$-rich foods were included at all sample times, smaller contributions of $\mathrm{Zn}$ from a wide variety of foods increased over time, especially after 1978. Thus the percentage contribution of $\mathrm{Zn}$ from a food which quantitatively remained constant at all sample times would decrease. In the surveys of 1969 and 1978, food consumption data are reported for sixty-eight items, which constituted the major foods in the Korean diet at that time. Less commonly consumed food items with smaller contributions of $\mathrm{Zn}$ may have been excluded from the dietary survey and so $\mathrm{Zn}$ intake may be marginally underestimated. The same is true for both $\mathrm{Ca}$ and phytate data. However, no additional major $\mathrm{Zn}-$, Ca- or phytatecontaining foods were discovered in the more comprehensive dietary surveys of 1988 and 1998, and it is likely that underestimates in the earlier surveys were minor.

Regarding the database of food product $\mathrm{Zn}$ levels used to calculate $\mathrm{Zn}$ intake, we preferentially utilized data from the analysis of specifically Korean foods ${ }^{(22)}$ (ninetyeight items) and augmented these data with published American (337 items) and Japanese (seventy-one items) values for food products consumed in Korea. In addition, substitute $\mathrm{Zn}$ values were used for 282 items. Since regional and national variations in the $\mathrm{Zn}$ content of food can occur depending on where it is produced, the calculated $\mathrm{Zn}$ intake values may not be entirely accurate; however, the relative comparison between sample years is valid because the same databases were used for the calculations at each time point.

During the period 1969-1988, Zn intake of South Koreans was around $4 \cdot 8-5 \cdot 8 \mathrm{mg} / \mathrm{d}$ which is equivalent to the low levels $(3 \cdot 7-5 \cdot 4 \mathrm{mg} / \mathrm{d})$ reported for developing countries $^{(2)}$. However, during the decade 1988-1998, the average $\mathrm{Zn}$ intake of South Koreans increased markedly to $7 \cdot 3 \mathrm{mg} / \mathrm{d}$, an amount lower than the average intake for adult UK men $(10 \cdot 2 \mathrm{mg} / \mathrm{d})$ in $2000 / 2001^{(3)}$ and healthy adult Americans $(10 \cdot 6-17 \cdot 5 \mathrm{mg} / \mathrm{d})$ in $2005 / 2006^{(29)}$. $\mathrm{Zn}$ intake of South Koreans is lower than the $\mathrm{Zn}$ intake level reported in China $(10.6 \mathrm{mg} / \mathrm{d})$ from the 2002 China Nationwide Nutrition and Health Survey, which used a similar nutritional survey scheme to that of the KNNS ${ }^{(6)}$. However, the $\mathrm{Zn}$ intake of Koreans in 1998 was higher than that in most developing countries, such as Thailand $(4.4 \mathrm{mg} / \mathrm{d})$, Egypt $(5 \cdot 2 \mathrm{mg} / \mathrm{d})$ or Mexico $(5 \cdot 4 \mathrm{mg} / \mathrm{d})^{(2)}$. According to our results, $\mathrm{Zn}$ intake in South Korea as a whole has been improving over the past three decades towards meeting the optimal $\mathrm{Zn}$ reference intake level. In the present study, the $\mathrm{Zn}$ intake $(7 \cdot 3 \mathrm{mg} / \mathrm{d})$ in 1998 was lower than in a previous report for $1995(10 \cdot 1 \mathrm{mg} / \mathrm{d})^{(4)}$. This discrepancy may be explained because $\mathrm{Zn}$ intake data in the present study were based on the analytical $\mathrm{Zn}$ content of Korean foods ${ }^{(23)}$ and these data were not available for the previous study's nutrient analysis ${ }^{(4)}$.

Since energy intake increased gradually from 1970 to $1998^{(19,30,31)}$, we considered the possibility that changes in total $\mathrm{Zn}$ intake were at least partly caused by corresponding changes in total food intake. Correcting $\mathrm{Zn}$ intake data for total energy intake gave values of $0 \cdot 45$, 0.50 and 0.62 mg Zn/MJ per d for 1978, 1988 and 1998 respectively, which indicates that despite an increase in energy intake, there was an even greater increase in $\mathrm{Zn}$ intake. Inspection of Fig. 1 clearly shows that the largest proportion of the marked increase in $\mathrm{Zn}$ intake between 1988 and 1998 came from increased consumption of animal meat and products.

In conclusion, economic prosperity and globalization in South Korea have brought profound changes in dietary habits that have been largely beneficial for $\mathrm{Zn}$ nutrition. Not only has $\mathrm{Zn}$ intake increased, but dietary intake of phytate, which reduces intestinal $\mathrm{Zn}$ absorption, has decreased and so dietary Zn bioavailability has improved. By 1998, average $\mathrm{Zn}$ intake levels were still below the reference intake for South Korea and other countries, and so we conclude that, within the study period, a substantial proportion of South Koreans may have been marginally Zn-deficient. Marked changes in the selection of particular Zn-rich foods could be regarded as indicators of economic prosperity and included meats, which increased, and cereals (particularly barley), which decreased over time. Dietary intakes of $\mathrm{Zn}, \mathrm{Ca}$ and phytate in rural populations 
have changed less than in urban populations and so marginal $\mathrm{Zn}$ deficiency is likely to be more prevalent in countryside areas. The results of the study may have implications for predicting changes in $\mathrm{Zn}$ nutrition in other Asian countries undergoing rapid economic growth and globalization, such as China and India.

\section{Acknowledgements}

The research was supported by ANU 2004 Research Grant and a grant of the Korea Health 21 R\&D Project, Ministry of Health and Welfare, Republic of Korea (HMP-00-B-2200000153). J.H.B. was funded by the Scottish Executive Rural and Environment Research and Analysis Directorate. None of the authors have any conflict of interest regarding the contents of this paper. Author contributions were as follows: I.-S.K. managed the nutrition survey data analysis; M.-S.D. wrote the manuscript; H.-R.C. and Y.-H.K. extracted and analysed the nutrition survey data sets and Korean economic status; J.H.B. analysed the data for nutrient intakes/ economic growth status.

\section{References}

1. Florentino RF \& Pedro RA (1992) Nutrition and socioeconomic development in Southeast Asia. Proc Nutr Soc 51, 93-104.

2. Gibson RS (2006) Zinc: the missing link in combating micronutrient malnutrition in developing countries. Proc Nutr Soc 65, 51-60.

3. Henderson L, Irving K, Gregory J, Bates CJ, Prentice A, Perks J, Swan G \& Farron M (2003) The National Diet and Nutrition Survey: Adults Aged 19 to 64 Years. vol. 3: Vitamin and Mineral Intake and Urinary Analytes. London: TSO.

4. Kwun IS \& Kwon CS (2000) Dietary molar ratios of phytate:zinc and millimolar ratios of phytate $\times$ calcium:zinc in South Koreans. Biol Trace Elem Res 75, 29-41.

5. Park SY, Paik HY, Skinner JD, Spindler AA \& Park HR (2004) Nutrient intake of Korean-American, Korean, and American adolescents. J Am Diet Assoc 104, 242-245.

6. Ma G, Li Y, Jin Y, Zhai F, Kok FJ \& Yang X (2007) Phytate intake and molar ratios of phytate to zinc, iron and calcium in the diets of people in China. Eur J Clin Nutr 61, 368-374.

7. Lonnerdal B (2000) Dietary factors influencing zinc absorption. J Nutr 130, S1378-S1383.

8. Hambidge M (2003) Underwood Memorial Lecture: human zinc homeostasis: good but not perfect. J Nutr 133, 1438S-1442S.

9. Kim J, Paik HY, Joung H, Woodhouse LR, Li S \& King JC (2007) Effect of dietary phytate on zinc homeostasis in young and elderly Korean women. J Am Coll Nutr 26, 1-9.

10. Miller LV, Krebs NF \& Hambidge KM (2007) A mathematical model of zinc absorption in humans as a function of dietary zinc and phytate. J Nutr 137, 135-141.

11. Raboy V (2003) myo-Inositol-1,2,3,4,5,6-hexakisphosphate. Phytochemistry 64, 1033-1043.

12. Sandstead HH (1991) Zinc deficiency. A public health problem? Am J Dis Child 145, 853-859.

13. Fordyce E, Forbes R, Robbins K \& Erdman J Jr (1987) Phytate $\times \mathrm{Ca}: \mathrm{Zn}$ molar ratios: are they predictive of $\mathrm{Zn}$ bioavailability? J Food Sci 52, 440-444.
14. Hotz C, Lowe NM, Araya M \& Brown KH (2003) Assessment of the trace element status of individuals and populations: the example of zinc and copper. J Nutr 133, S1563-S1568.

15. Ferguson EL, Gibson RS, Thompson LU \& Ounpuu S (1989) Dietary calcium, phytate, and zinc intakes and the calcium, phytate, and zinc molar ratios of the diets of a selected group of East African children. Am J Clin Nutr 50, 1450-1456.

16. Manary MJ, Hotz C, Krebs NF, Gibson RS, Westcott JE, Arnold T, Broadhead RL \& Hambidge KM (2000) Dietary phytate reduction improves zinc absorption in Malawian children recovering from tuberculosis but not in well children. J Nutr 130, 2959-2964.

17. Regmi A \& Dyck J (2001) Effects of urbanization on global food demand. In Changing Structure of Global Food Consumption and Trade. Agriculture and Trade Report no. WRS01-1, pp. 23-30 [A Regmi, editor]. Washington, DC: Economic Research Service, US Department of Agriculture; available at http://www.ers.usda.gov/publications/wrs011/wrs011e.pdf

18. Dyck JH \& Nelson KE (2002) Structure of the Global Markets for Meat. Agriculture Information Bulletin no. 785. Washington, DC: Market and Trade Economics Division, Economic Research Service, US Department of Agriculture.

19. Ministry of Health and Welfare of the Republic of Korea (1971, 1980, 1990, 2000) National Nutrition Survey Reports: In-Depth Analysis on National Health and Nutrition Survey. Seoul: MHWRK.

20. Ministry of Health and Welfare of the Republic of Korea (1999) Data Manual on 1998 National Health and Nutrition Survey. Seoul: MHWRK.

21. Korean Nutrition Society (2005) Dietary Reference Intakes for Koreans, 1st ed. Seoul: Ministry of Health and Welfare of the Republic of Korea.

22. Lee JY, Paik HY \& Joung H (1998) Supplementation of Zn nutrient database and evaluation of $\mathrm{Zn}$ intake of Korean adults living in rural area. Kor J Nutr 31, 1324-1337.

23. Nam GY (2001) Analysis of phytate content in Koreans food items and effect of cooking on phytate content and zinc bioavailability in Korean diet. MSc Thesis, Seoul National University.

24. Heston S, Summers R \& Aten B (2002) Penn World Table Version 6.1. Philadelphia, PA: Center for International Comparisons, University of Pennsylvania.

25. Kwon CS, Kountouri AM, Mayer C, Gordon MJ, Kwun IS \& Beattie JH (2007) Mononuclear cell metallothionein mRNA levels in human subjects with poor zinc nutrition. BrJ Nutr 97, 247-254.

26. Food and Agriculture Organization of the United Nations/ World Health Organization/International Atomic Energy Authority (1996) Trace Elements in Human Nutrition and Health. Geneva: WHO.

27. Gibson RS, Smit Vanderkooy PD \& Thompson L (1991) Dietary phytate $\times$ calcium/zinc millimolar ratios and zinc nutriture in some Ontario preschool children. Biol Trace Elem Res 30, 87-94.

28. Food and Agriculture Organization of the United Nations (2008) FAOSTAT on-line statistical service. Rome: FAO; available at http://faostat.fao.org/default.aspx

29. US Department of Agriculture, Agricultural Research Service (2008) Nutrient Intakes 2005/2006. Food Surveys Products and Services. http://www.ars.usda.gov/Services/docs.htm? docid=17041 (accessed September 2008)

30. South Korean National Statistical Office (1999) 1998 Korean national Nutrition Survey Reports I \& II (in Korean). Seoul: National Statistical Office; available at www.kosis.kr

31. South Korean Rural Development Administration \& Rural Nutrition Institute (1999) Food Supply and Consumption Table (in Korean). Seoul: South Korean Rural Development Administration and Rural Nutrition Institute; available at http://www.krei.re.kr/kor/main.php 